\title{
Multiple scalp metastases from colonic neuroendocrine carcinoma: case report and literature review
}

\author{
Shao-min Wang, Meng Ye $e^{*}$ and Shu-min Ni
}

\begin{abstract}
Background: Colonic neuroendocrine neoplasms (NENs) are relatively rare tumors with an incidence rate of $0.11-0.21 / 100,000$. NENs account for approximately $0.4 \%$ of colorectal neoplasms. Cutaneous metastases of colonic neuroendocrine carcinomas (NECs) are very infrequent, while cases of scalp metastasis are even fewer. Cutaneous metastases are more rare than visceral metastases and usually develop later; therefore, cutaneous metastases as initial distant metastases can be easily overlooked. This is the second case report of a colonic NEC with scalp metastasis. Compared with the previous case, in this instance scalp metastasis developed before visceral metastasis, and the cutaneous lesions were confined to the scalp alone.

Case presentation: A 62-year-old Chinese man, who had undergone radical surgery for a "locoregional" colonic NEC one and half months before, came to our hospital for adjuvant chemotherapy. We found multiple scalp nodules during physical examination. Moreover, these nodules had occurred and had not been detected prior to the patient undergoing radical surgery. The scalp nodules proved to be metastases from colonic NEC as determined using pathological and immunohistochemical examinations following lumpectomy. After one and half months, visceral metastases were detected in this patient. Ultimately, the patient died two months later.

Conclusions: In this report an unusual case of a colonic NEC with initial distant metastasis confined to the scalp is presented. This case is unusual because of the development of cutaneous metastasis before visceral metastasis. The scalp metastasis were initially overlooked, leading to inaccurate staging and radical surgery that was not curative. This demonstrates that distant metastasis can occur during the early phase of tumor growth in these aggressive lesions. Thus, the possibility of distant metastases should be assessed in the initial work up to avoid mistaken clinical staging especially when distant metastases occur only in skin.
\end{abstract}

Keywords: Colon cancer, Neuroendocrine carcinoma, Scalp, Metastasis

\section{Background}

Neuroendocrine neoplasms (NENs) are rare tumors originating from neuroendocrine cells and include a series of heterogeneous tumors. Their presentation can be indolent, low-grade malignant or high-grade malignant. These tumors can synthesize, store and secrete peptide hormones. Excessive hormones can cause corresponding clinical symptoms. According to the degree of differentiation, NENs have been divided into well differentiated NENs and poorly differentiated NENs in the 2010 World

\footnotetext{
* Correspondence: 29091740@qq.com

Department of Medical Oncology, Affiliated Hospital, School of Medicine,

Ningbo University, No. 247 Renmin Road, Ningbo 315020, Zhejiang Province, China
}

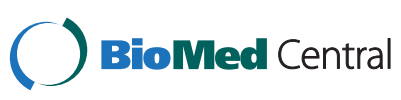

(c) 2014 Wang et al.; licensee BioMed Central Ltd. This is an Open Access article distributed under the terms of the Creative Commons Attribution License (http://creativecommons.org/licenses/by/4.0), which permits unrestricted use, distribution, and reproduction in any medium, provided the original work is properly credited. The Creative Commons Public Domain Dedication waiver (http://creativecommons.org/publicdomain/zero/1.0/) applies to the data made available in this article unless otherwise stated.
Health Organization classification of tumors of the digestive system, with the former being termed a neuroendocrine tumor (NET), and the latter, a neuroendocrine carcinoma (NEC) [1]. Cases of colonic NECs are very unusual and data from the Norwegian Registry of Cancer from 1993-2004 showed that the incidence rate of colonic NENs was $0.25 / 100,000$ and $31.5 \%$ of colonic NENs were classified as NECs [2]. Distant metastasis of NECs mostly occurred in the viscera, while cases of scalp metastasis were rarely reported. A literature review in PubMed revealed only four case reports [3-6], however, primary colonic NEC was present in only one case [6]; these cases are summarized in Table 1. 
Table 1 Cases of scalp metastases of NEC reported in the literature

\begin{tabular}{|c|c|c|c|c|c|}
\hline Ref & Sex/Age & Primary tumor & Metastasis to other sites & $\begin{array}{l}\text { Cutaneous metastases } \\
\text { before visceral metastases }\end{array}$ & $\begin{array}{l}\text { Number of scalp } \\
\text { metastasis }\end{array}$ \\
\hline [3] & $F / 31$ & Uterine cervix & Bone, lung, pleura, spinal cord, lymph nodes & No & 2 \\
\hline [4] & $F / 33$ & Uterine & $\begin{array}{l}\text { Cutaneous metastases of chest, back, abdomen, axilla } \\
\text { and neck }\end{array}$ & Yes & $>1$ \\
\hline [5] & $M / 20$ & Bladder & Lung, retroperitoneal lymph nodes, skin of other sites & No & 1 \\
\hline [6] & $M / 42$ & Colon & $\begin{array}{l}\text { Liver, sphenoid, cavernous sinuses, bone, cutaneous } \\
\text { metastasis of shoulder }\end{array}$ & No & 1 \\
\hline Our case & $M / 62$ & Colon & Liver, pancreas, lymph nodes & Yes & $>3$ \\
\hline
\end{tabular}

We now report a second case of a colonic NEC with multiple scalp metastases. Furthermore, this case has three features: (1) cutaneous metastases developed only in the scalp with no cutaneous metastases found at other sites; (2) there were multiple scalp metastases $(>3)$; and (3) scalp metastases developed before visceral metastases. This case report, therefore, will focus attention on scalp metastases of an NEC. We have also reviewed the literature concerning gastroenteropancreatic neuroendocrine carcinomas (GEP-NECs) in this article.

\section{Case presentation}

The patient was a 62-year-old man who was admitted to a local hospital because of abdominal pain and abdominal distension. Colonoscopy revealed a colon mass and a computed tomography (CT) scan of the abdomen showed that the mass infiltrated the serosa of the transverse colon, which was adjacent to the omentum majus with mesenteric lymph node metastases. The patient then went to a cancer hospital where a CT scan of his thorax and abdomen showed no distant metastases. Radical surgery was performed to remove his colon cancer on Feb 16th, 2013. Because the primary tumor was removed in a different hospital, we were unable to acquire a specimen of the resected primary tumor, however, we were able to obtain the pathological examination report. According to the report, the primary tumor was a poorly differentiated NEC of the right colon (grade 3) with a mass size of $9 \times 5 \times 3.5 \mathrm{~cm}$. The tumor infiltrated the full thickness of the intestinal wall and extended into the extraserosal fibrous and adipose tissue, and 5/19 excised lymph nodes were positive for metastases. There were vessel cancer emboli, neural invasion, four cancer nodules around the tumor, four cancer nodules on the mesenterium and five cancer nodules on the omentum majus. The immunohistochemical report showed that tumor cells were stained positive for cytokeratin AE1/3, cytokeratin CAM5.2, chromogranin A (CgA), synaptophysin (Syn), CD56 antigen, CDX-2 and Ki-67 (approximately 30-50\%).

The patient came to our hospital for adjuvant chemotherapy on March 28th, 2013. Multiple nodules in the scalp were found using physical examination $(>3)$ (Figure 1) and no cutaneous nodules were palpated at other sites. The patient recalled that he had some reddish papules on his scalp before surgery, but he did not mention them to the surgeon. These papules became gradually larger and formed multiple nodules. Laboratory tests done on admission showed that carbohydrate antigen 19-9 was 51.27 U/mL (normal, <37 U/mL), carbohydrate antigen 125 was $95.09 \mathrm{U} / \mathrm{mL}$ (normal, <35 U/mL) and neuron-specific enolase (NSE) was $123.9 \mu \mathrm{g} / \mathrm{L}$ (nor$\mathrm{mal},<17 \mu \mathrm{g} / \mathrm{L})$. Magnetic resonance of the head showed multiple space-occupying lesions with a rich blood supply in the soft tissue of his scalp (Figure 2). Our patient received one cycle of systemic chemotherapy with a regimen of etoposide $100 \mathrm{mg} / \mathrm{m}^{2}$ IV on days $1-3$ and cisplatin $25 \mathrm{mg} / \mathrm{m}^{2}$ IV on days $1-3$.

He underwent a lumpectomy and transfer of a skin flap after chemotherapy. The largest nodule was about $2.5 \mathrm{~cm}$ in diameter, and it was removed during surgery. Pathological examination of the scalp nodule showed that the size of tumor was $2 \times 2 \times 1 \mathrm{~cm}$. Hematoxylineosin staining showed that the scalp metastasis was composed of small to medium-sized cells with minimal cytoplasm, irregularly shaped nuclei with granular

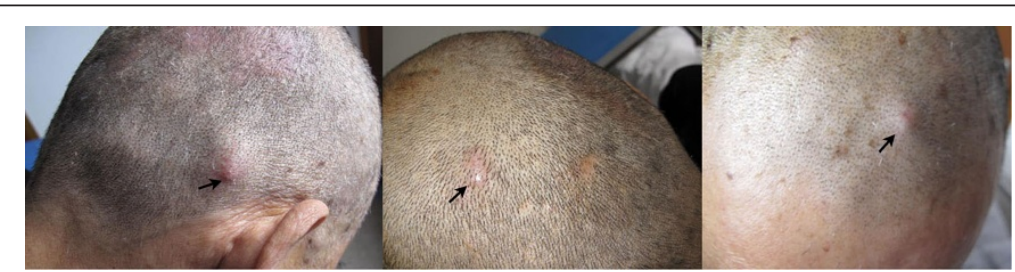

Figure 1 Multiple reddish nodules in the subcutis of the scalp. 


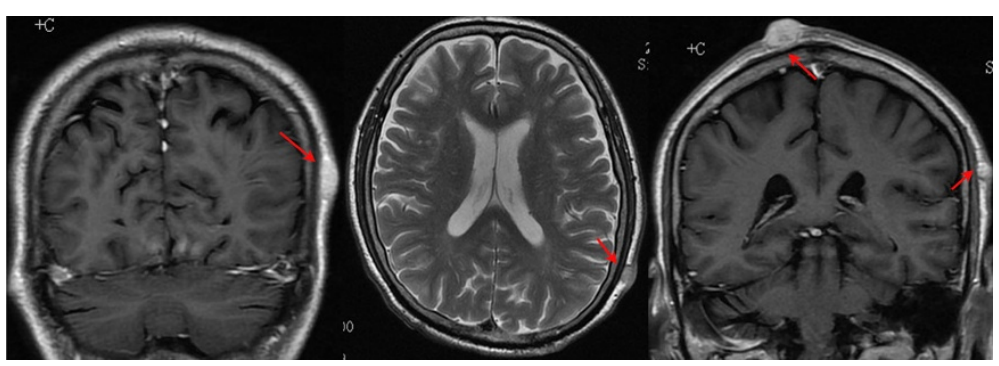

Figure 2 Head MRI showed multiple lesions in the soft tissue of the scalp.

chromatin and prominent nucleoli in some cells. Tumor cells were arranged in diffuse and nesting patterns and mitoses were numerous (24 mitoses per 10 high power fields) (Figure 3). Immunohistochemical analyses showed that tumor cells stained positive for CD56 (weak), Syn (diffuse), CDX-2 (strong), pan-cytokeratin, cytokeratin 8, cytokeratin CAM5.2 and Ki-67, with the Ki-67 index reaching up to $60 \%$ (Figure 4 ). On the other hand, tumor cells stained negative for CK20, transcription termination factor 1 (TTF-1), melanoma antibody (HMB45) and CgA (Figure 5). On the basis of the pathological examination and medical history, the metastatic tumor of the scalp was considered to be a poorly differentiated carcinoma that originated from the colon with necrosis and neuroendocrine differentiation (NEC grade 3 ).

But other scalp nodules became larger and new nodules appeared after surgery. The patient received one additional cycle of the same chemotherapy regimen after April 23rd, 2013. Tumor progression was considered to have occurred once scalp nodules further increased in size and NSE levels further rose after chemotherapy. A CT scan of the patient's abdomen was performed on May 14th, 2013. The scan showed that he had liver, pancreatic and lymph node metastases. Once visceral metastases were found, the patient received subcutaneous injection of octreotide acetate $0.1 \mathrm{mg}$ per 8 hours for three days as of May 26th, 2013, and intramuscular injection of $20 \mathrm{mg}$ octreotide acetate microspheres every
28 days three days later. Finally the patient received palliative and supportive treatment, and died of disease progression one month later.

\section{Conclusions}

The gastrointestinal tract constitutes the most common site of origin of extra-pulmonary NECs, which can originate anywhere in the gastrointestinal tract [7]. The incidence rate of GEP-NENs is about 2-5/100,000 [8,9]. Functional NET is often accompanied by corresponding neuroendocrine symptoms. On the contrary, NECs are usually non-functional and without neuroendocrine symptoms. As a result, early-stage patients with NECs often have no specific signs or symptoms making early diagnosis very difficult, such that a majority of these patients already have disseminated disease at diagnosis [10-12]. The annual incidence of colonic NENs is $0.11-0.21 / 100,000$ and NENs make up $0.4 \%$ of colorectal neoplasms [1]. Consequently when a mass is discovered in the colon, we seldom consider a diagnosis of a colonic NEC; rather a diagnosis of a colon adenocarcinoma is considered first. NSE has been shown to have a high diagnostic value in NECs [13,14]. The likelihood of an NEC is high when a patient has a colon mass that is accompanied by elevated serum NSE. At the time of initial diagnosis, extensive metastases usually do not appear in colonic adenocarcinoma, but distant metastasis often developed in NECs because of its invasive nature.

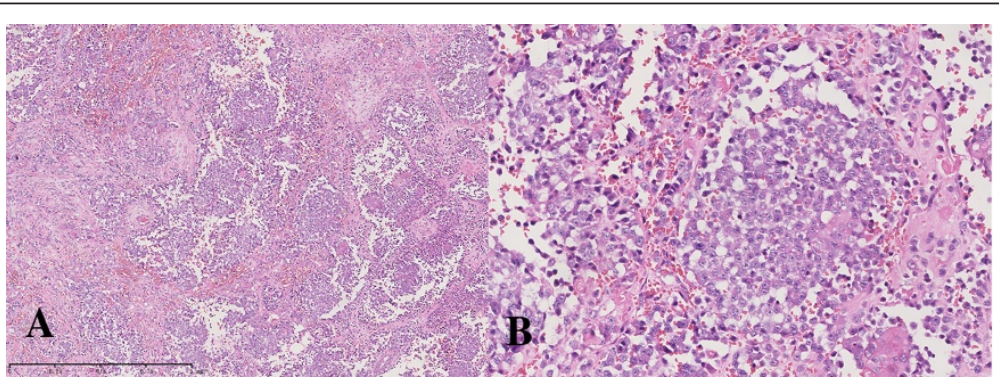

Figure 3 Microscopic features of scalp nodule. (A) Tumor cells arranged in diffuse and nesting patterns in the subcutis (hematoxylin-eosin staining, $\times 50$ ). (B) Irregular and small to medium-sized tumor cells with scanty cytoplasm, hyperchromatic nuclei and distinct nucleoli in some cells (hematoxylin-eosin staining, $\times 400$ ). 


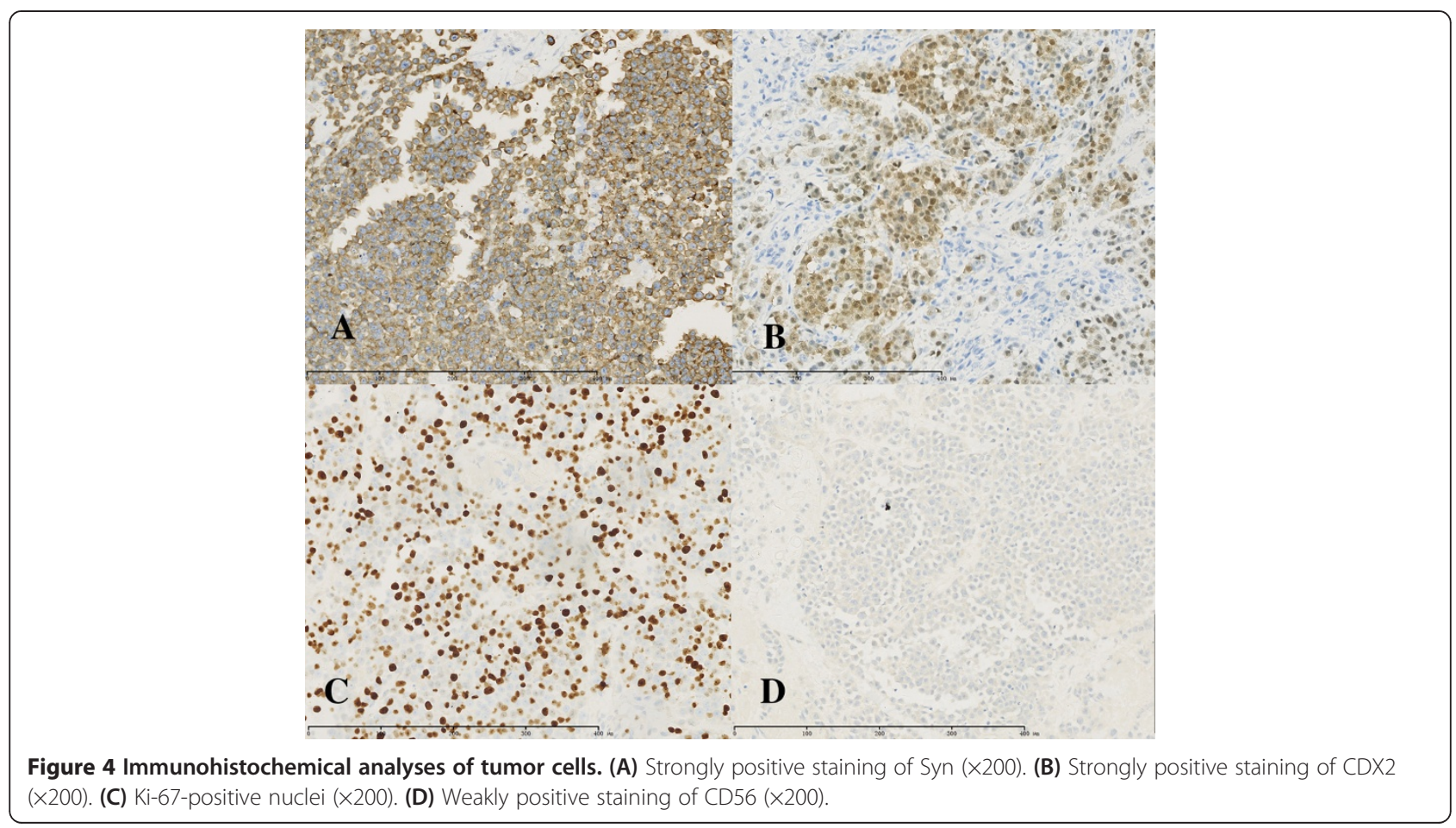

When this case was first diagnosed from the CT scan, this patient was considered to have regional disease and underwent radical surgery with curative intent. If scalp metastases had been found before surgery, a palliative operation may have been more suitable for this patient. Because of the high incidence of distant metastasis in NECs, when the patient was diagnosed with an NEC, a comprehensive preoperative physical examination and staging evaluation were necessary. When morphological imaging fails to find distant metastasis and distant metastasis is highly suspected, a positron-emission tomographyCT (PET-CT) examination should be done to acquire

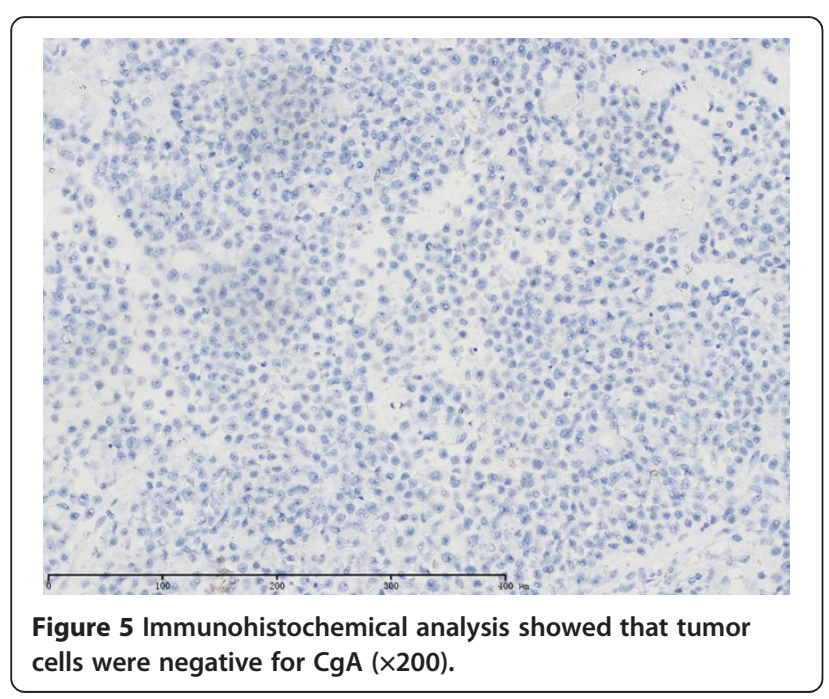

accurate clinical staging. Since cutaneous metastasis are infrequent in NECs and often overlooked, scalp metastases were not found prior to surgery that resulted in wrong preoperative staging in this case. From the medical history of this patient, scalp metastases occurred earlier than visceral metastases. So when the initial diagnosis of a GEPNEC was made, we should have paid attention to whether scalp or cutaneous metastases were present.

In terms of the pathological diagnosis of NENs, grading of NENs is done according to the degree of proliferative activity of tumor cells, which is measured using two criteria, mitotic figures and (or) Ki-67 index. NENs of grade 1 or 2 are NETs, and NENs of grade 3 are NECs. Tumor cells of NETs are arranged in a characteristic organoid shape with nesting, and trabecular or gyriform patterns [15]. The cells are relatively uniform with round to oval nuclei having indistinct nucleoli and a coarsely granular chromatin pattern [1], expressing general markers of neuroendocrine differentiation (usually diffuse and intense CgA and Syn) [1]. In contrast, NECs have a more sheetlike or diffuse architecture with irregular nuclei and less cytoplasmic granularity [15]. Immunoexpression of neuroendocrine markers is more limited (diffuse expression of Syn, faint or focal staining for CgA) [1] .

Representative NECs include small cell NECs (small cell carcinoma for short) and large cell NECs, while morphology resembles that of the corresponding lung tumor. Tumor cells of small cell carcinoma are small, round or oval like lymphocytes and some cells are elongated like fusiform; moreover cytoplasm is minimal. In this kind of 
tumor cell, nuclei are finely speckled and hyperchromatic, the nucleoli are inconspicuous and mitoses are numerous. Small cell carcinoma takes on a diffuse distribution or nesting arrangement, often accompanied by necrosis. Cells of small cell carcinoma are generally less than three times the size of lymphocytes. However, cells of large cell NECs are generally larger than three times the size of lymphocytes with coarse granular chromatin, prominent nucleoli and abundant cytoplasm. In large cell NECs, necrosis and mitoses are common, and the tumor takes on organoid, nesting, trabecular, rosette-like or palisading pattern.

Hematoxylin-eosin staining showed that in this case the scalp metastasis consisted of small to medium-sized tumor cells arranged in nesting patterns, which were in line with the features of an NEC. Further immunohistochemical analyses showed that tumor cells stained positive for Syn and CD56, which are neuroendocrine markers, while no staining for $\mathrm{CgA}$ indicated that the tumor was poorly differentiated. Nuclear staining of Ki-67 was positive and the Ki-67 index reached 60\%, which was in accord with a grade 3 NEC. Cutaneous metastasis of NECs should be differentiated from Merkel cell carcinoma (MCC) and its origin should be investigated. CK20 is commonly positive in MCC, but it is usually negative in NECs at other sites [16]. CDX2 and TTF-1 are highly specific markers of gastrointestinal tract NENs and pulmonary NENs, respectively $[17,18]$. Tumor cells of scalp nodules were positive for CDX2, but negative for TTF-1 and CK20 in this case; therefore, scalp nodules were not MCC and originated from the colon.

Cases of GEP-NECs are rare and just a few large-scale clinical studies have been conducted. Because the clinical behavior of GEP-NECs is similar to that of small cell lung cancer (SCLC), treatment modalities are usually based on those prescribed for SCLC; therefore, adjuvant treatment with chemotherapy and/or radiotherapy should be given even after a definitive complete surgical resection [7]. The recommended regimen of adjuvant chemotherapy involves the combination of etoposide and cisplatin/carboplatin [19], and usually 4-6 cycles are administered [7]. Carboplatin and irinotecan seemed to be at least equally effective compared with cisplatin and etoposide [7,20,21]. Indeed, irinotecan was even better than etoposide in a multicenter retrospective analysis [22]. Second-line therapy for NECs is based on that used to treat relapsed SCLC, such as irinotecan, topotecan, paclitaxel, docetaxel, vinorelbine and gemcitabine [7]. In addition, a retrospective study showed that temozolomide, either alone or in combination with capecitabine or bevacizumab, attained a response rate of $33 \%$ as second-line therapy in patients with mostly GEP-NECs, but capecitabine or bevacizumab did not seem to have any additional effect compared to temozolomide [23]. Although the mammalian target of rapamycin signaling pathway inhibitor everolimus elicits a good response in patients with well differentiated NET, those with NECs are usually excluded from clinical trials (RADIANT 2, RADIANT3) because of their aggressive nature $[24,25]$. Thus, whether patients with NECs will respond to everolimus still needs to be confirmed. Somatostatin analogues (SSA) helped to control the syndrome and reduce circulating markers in GEP-NENs [26,27], but their antiproliferative effect was much less clear and disease stabilization was more common [28-30]. The combination of SSA and chemotherapy can be synergistic in the treatment of NETs [31], however, SSA with chemotherapy to treat NECs has only been evaluated in a phase II study [32]. Currently there is no evidence regarding the efficacy of the combination of SSA and chemotherapy in the treatment of GEP-NECs. Similarly, the vascular endothelial growth factor receptor-tyrosine kinase inhibitor sunitinib has not been evaluated in the treatment of NECs [33]. Our patient received etoposide and cisplatin as firstline chemotherapy, but did not respond. Since the patient had an NEC, SSA did not have any therapeutic effect.

Prognostic factors were also analyzed in NECs. Several studies have illustrated that the extent of the disease, patient performance status, Ki-67 index, maximal standard uptake value of a PET-CT examination and primary site were the best predictors of survival or response, however, patients with primary colonic NECs seemed to have shorter survival $[8,11,12,34-36]$. Blood levels of platelets and lactate dehydrogenase were strong predictors of survival as well [12]. The tumor of this patient, derived from the colon, was extensive with a high $\mathrm{Ki}-67$ index, indicative of a poor prognosis. Postoperative survival of this patient was only five months. Primary drug resistance to chemotherapy occurred in this patient and receiving octreotide microspheres did not cause tumor remission. In conclusion, NECs are extremely high-grade malignancies, and therapeutic efficacy and prognosis are poor in patients with these performances.

\section{Consent}

Written informed consent was obtained from the patient's wife for publication of this case report and any accompanying images. A copy of the written consent is available for review by the Editor of this journal.

\section{Competing interests}

The authors declare that they have no competing interests.

\section{Authors' contributions}

SMW reviewed the literature, prepared the data, and also drafted and revised the manuscript. MY made substantial contributions to the conception and design of the study, and also gave final approval of the version to be published. SMN participated in the design and coordination of the study. All authors read and approved the final manuscript. 


\section{Acknowledgements}

We wish to thank Yi-di Zhao, who is a freshman medical student at Australia Catholic University, for language editing as well as the members of the Ningbo Pathology Center for providing the figures.

Received: 13 February 2014 Accepted: 24 April 2014 Published: 1 May 2014

\section{References}

1. Bosman FT, Carneim F, Hruban RH, Theise ND: WHO Classification of Tumours of the Digestive System. Lyon: IARC Press; 2010.

2. Hauso O, Gustafsson BI, Kidd M, Waldum HL, Drozdov I, Chan AK, Modlin IM: Neuroendocrine tumor epidemiology: contrasting Norway and NorthAmerica. Cancer 2008, 113:2655-2664.

3. Chung WK, Yang JH, Chang SE, Lee MW, Choi JH, Moon KC, Koh JK: A case of cutaneous metastasis of small-cell neuroendocrine carcinoma of the uterine cervix. Am J Dermatopathol 2008, 30:636-638.

4. Fogaça MF, Fedorciw BJ, Tahan SR, Johnson R, Federman M: Cutaneous metastasis of neuroendocrine carcinoma of uterine origin. J Cutan Pathol 1993, 20:455-458

5. Lee WJ, Kim CH, Chang SE, Lee MW, Choi JH, Moon KC, Koh JK: Cutaneous metastasis from large-cell neuroendocrine carcinoma of the urinary bladder expressing CK20 and TTF-1. Am J Dermatopathol 2009, 31:166-169.

6. Luh JY, Han ES, Simmons JR, Whitehead RP: Poorly differentiated colon carcinoma with neuroendocrine features presenting with hypercalcemia and cutaneous metastases: case report and review of the literature. $\mathrm{Am} J$ Clin Oncol 2002, 25:160-163.

7. Strosberg JR, Coppola D, Klimstra DS, Phan AT, Kulke MH, Wiseman GA, Kvols LK: The NANETS consensus guidelines for the diagnosis and management of poorly differentiated (high-grade) extrapulmonary neuroendocrine carcinomas. Pancreas 2010, 39:799-800.

8. Yao JC, Hassan M, Phan A, Dagohoy C, Leary C, Mares JE, Abdalla EK, Fleming JB, Vauthey JN, Rashid A, Evans DB: One hundred years after carcinoid: epidemiology of and prognostic factors for neuroendocrine tumors in 35, 825 cases in the United States. J Clin Oncol 2008, 26:3063-3072

9. Niederle MB, Hackl M, Kaserer K, Niederle B: Gastroenteropancreatic neuroendocrine tumours: the current incidence and staging based on the WHO and European Neuroendocrine Tumour Society classification: an analysis based on prospectively collected parameters. Endocr Relat Canc 2010, 17:909-918.

10. Ahlman H, Nilsson O, McNicol AM, Ruszniewski P, Niederle B, Ricke J, Jensen R, Kos-Kudła B, Oberg K, O'Connor JM, Pavel ME, Vullierme MP: Poorly-differentiated endocrine carcinomas of midgut and hindgut origin. Neuroendocrinology 2008, 87:40-46.

11. Brenner B, Tang LH, Klimstra DS, Kelsen DP: Small-cell carcinomas of the gastrointestinal tract: a review. J Clin Oncol 2004, 22:2730-2739.

12. Sorbye H, Welin S, Langer SW, Vestermark LW, Holt N, Osterlund P, Dueland S, Hofsli E, Guren MG, Ohrling K, Birkemeyer E, Thiis-Evensen E, Biagini M, Gronbaek H, Soveri LM, Olsen IH, Federspiel B, Assmus J, Janson ET, Knigge U: Predictive and prognostic factors for treatment and survival in 305 patients with advanced gastrointestinal neuroendocrine carcinoma (WHO G3): The NORDIC NEC study. Ann Oncol 2013, 24:152-160.

13. Lindholm DP, Oberg K: Biomarkers and molecular imaging in gastroenteropancreatic neuroendocrine tumors. Horm Metab Res 2011, 43:832-837.

14. Korse CM, Taal BG, Vincent A, van Velthuysen ML, Baas P, Buning-Kager JC, Linders TC, Bonfrer JM: Choice of tumourmarkers in patients with neuroendocrinetumours is dependent on the histologicalgrade. A marker study of Chromogranin A, Neuron specific enolase, Progastrin-releasing peptide and cytokeratin fragments. Eur $J$ Cancer 2012, 48:662-671.

15. Klimstra DS, Modlin IR, Coppola D, Lloyd RV, Suster S: The pathologic classification of neuroendocrine tumors: a review of nomenclature, grading, and staging systems. Pancreas 2010, 39:707-712.

16. Chan JK, Suster S, Wenig BM, Tsang WY, Chan JB, Lau AL: Cytokeratin 20 immunoreactivity distinguishes Merkel cell (primary cutaneous neuroendocrine) carcinomas and salivary gland small cell carcinomas from small cell carcinomas of various sites. Am J Surg Pathol 1997, 21:226-234
17. Saqi A, Alexis D, Remotti F, Bhagat G: Usefulness of CDX2 and TTF-1 in differentiating gastrointestinal from pulmonary carcinoids. Am J Clin Pathol 2005, 123:394-404.

18. Lin X, Saad RS, Luckasevic TM, Silverman JF, Liu Y: Diagnostic value of CDX-2 and TTF-1 expressions in separating metastatic neuroendocrine neoplasm of unknown origin. Appl Immunohistochem Mol Morphol 2007, 15:407-414

19. Mitry E, Baudin E, Ducreux M, Sabourin JC, Rufié P, Aparicio T, Aparicio T, Lasser P, Elias D, Duvillard P, Schlumberger M, Rougier P: Treatment of poorly differentiated neuroendocrine tumours with etoposide and cisplatin. Br J Canc 1999, 81:1351-1355.

20. Di Meglio G, Massacesi C, Radice D, Boselli S, Pelosi G, Squadroni M, Spada F, Lorizzo K, De Braud FG, Fazio N: Carboplatin with etoposide in patients with extrapulmonary"aggressive"neuroendocrine carcinoma [meeting abstract]. J Clin Oncol 2010, 28(Suppl 15):e13072.

21. Okita NT, Kato K, Takahari D, Hirashima Y, Nakajima TE, Matsubara J, Hamaguchi T, Yamada Y, Shimada Y, Taniguchi H, Shirao K: Neuroendocrine tumors of the stomach: chemotherapy with cisplatin plus irinotecan is effective for gastric poorly-differentiated neuroendocrine carcinoma. Gastric Canc 2011, 14:161-165.

22. Yagamuchi T, Machida N, Kasuga A, Takahashi H, Sudo K, Nishina T, Tobimatsu K, Furuse J, Boku N: Multiple retrospective analysis of systemic chemotherapy in poorly differentiated neuroendocrine carcinoma of the digestive system [meeting abstract]. J Clin Oncol 2012, 30(Suppl 4):274.

23. Welin S, Sorbye H, Sebjornsen S, Knappskog S, Busch C, Oberg K: Clinical effect of temozolomide based chemotherapy in poorly differentiated endocrine carcinoma after progression on first-line chemotherapy. Cancer 2011, 117:4617-4622.

24. Yao JC, Shah MH, Ito T, Bohas CL, Wolin EM, Van Cutsem E, Hobday TJ, Okusaka T, Capdevila J, de Vries EG, Tomassetti P, Pavel ME, Hoosen S, Haas T, Lincy J, Lebwohl D, Öberg K: Everolimus for advanced pancreatic neuroendocrine tumors. N Engl J Med 2011, 364:514-523.

25. Pavel ME, Hainsworth JD, Baudin E, Peeters M, Hörsch D, Winkler RE, Klimovsky J, Lebwohl D, Jehl V, Wolin EM, Oberg K, Van Cutsem E, Yao JC: Everolimus plus octreotide long-acting repeatable for the treatment of advanced neuroendocrine tumours associated with carcinoid syndrome (RADIANT-2): a randomised, placebo-controlled, phase 3 study. Lancet 2011, 378:2005-2012.

26. Arnold R, Simon B, Wield M: Treatment of neuroendocrine GEP tumours with somatostatin analogues:a review. Digestion 2000, 62(Suppl 1):84-91.

27. Lamberts SWJ, Krenning EP, Reubi JC: The role of somatostain and its analogs in the diagnosis and treatments of tumors. Endocrinol Rev 1991, 12:450-482.

28. Arnold R, Trautmann ME, Creutzfeldt W, Benning R, Benning M, Neuhaus $C$ Jürgensen R, Stein K, Schäfer H, Bruns C, Dennler HJ: Somatostatin analogue octreotide and inhibition of tumour growth in metastatic endocrine gastroenteropancreatic tumors. Gut 1996, 38:430-438.

29. di Bartolomeo M, Bajetta E, Buzzoni R, Mariani L, Carnaghi C, Somma L, Zilembo N, di Leo A: Clinical efficacy of octreotide in the treatment of metastatic neuroendocrine tumors. A study by the Italian Trials in Medical Oncology Group. Cancer 1996, 77:402-408.

30. Aparicio T, Ducreux M, Baudin E, Sabourin JC, De Baere T, Mitry E, Schlumberger $\mathrm{M}$, Rougier P: Antitumor activity of somatostatin analogues in progressive metastatic neuroendocrine tumors. Eur J Canc 2001, 37:1014-1019

31. Brizzi MP, Berruti A, Ferrero A, Milanesi E, Volante M, Castiglione F, Birocco N, Bombaci S, Perroni D, Ferretti B, Alabiso O, Ciuffreda L, Bertetto O, Papotti M, Dogliotti L: Continuous 5-fluorouracil infusion plus long acting octreotide in advanced well-differentiated neuroendocrine carcinomas. A phase II trial of the Piemonte oncology network. BMC Canc 2009, 3:388.

32. Correale P, Sciandivasci A, Intrivici C, Pascucci A, Del Vecchio MT, Marsili S, Savelli V, Voltolini L, Di Bisceglie M, Guarnieri A, Gotti G, Francini G: Chemo-hormone therapy of non well-differentiated endocrine tumours from different anatomic sites with cisplatinum, etoposide and slow release lanreotide formulation. Br J Canc 2007, 96:1343-1347.

33. Raymond E, Dahan L, Raoul JL, Bang YJ, Borbath I, Lombard-Bohas C, Valle J, Metrakos P, Smith D, Vinik A, Chen JS, Hörsch D, Hammel P, Wiedenmann B, Van Cutsem E, Patyna S, Lu DR, Blanckmeister C, Chao R, Ruszniewski P: Sunitinib malate for the treatment of pancreatic neuroendocrine tumors. N Engl J Med 2011, 364:501-513. 
34. Binderup T, Knigge U, Loft A, Federspiel B, Kjaer A: 18 F-fluorodeoxyglucose positron emission tomography predicts survival of patients with neuroendocrine tumors. Clin Canc Res 2010, 16:978-985.

35. Rothenstein J, Cleary SP, Pond GR, Dale D, Gallinger S, Moore MJ, Brierley J, Siu LL: Neuroendocrine tumors of the gastrointestinal tract: a decade of experience at the Princess Margaret Hospital. Am J Clin Oncol 2008, 31:64-70.

36. Walenkamp AM, Sonke GS, Sleijfer DT: Clinical and therapeutic aspects of extrapulmonary small cell carcinoma. Canc Treat Rev 2009, 35:228-236.

doi:10.1186/1471-2407-14-305

Cite this article as: Wang et al: Multiple scalp metastases from colonic neuroendocrine carcinoma: case report and literature review. BMC Cancer 2014 14:305.

\section{Submit your next manuscript to BioMed Central and take full advantage of:}

- Convenient online submission

- Thorough peer review

- No space constraints or color figure charges

- Immediate publication on acceptance

- Inclusion in PubMed, CAS, Scopus and Google Scholar

- Research which is freely available for redistribution 